\title{
28 Research Soure \\ Comparison of the Clinical Characteristics of Patients With COVID-19 in Suining and Wuhan
}

\section{Xiao-juan Wu}

Suining Central Hospital https://orcid.org/0000-0001-8606-5347

\section{Chao-Ping Wang}

Suining Central Hospital

\section{Xiao-Bin Luo}

Suining Central Hospital

\section{Gao-Yan He}

Suining Central Hospital

\section{Bao-Lin Jia}

Suining Central Hospital

Jing Wang

Chongqing Medical University

Li Luo

Suining Central Hospital

\section{Rong Qiu}

Suining Central Hospital

\section{Zheng-Guang He}

Suining Central Hospital

Min-Chao Li (D 15923325923@163.com )

\section{Research}

Keywords: Coronavirus disease 2019, severe acute respiratory syndrome coronavirus 2, China's fourth-tier cities, Wuhan

Posted Date: June 8th, 2020

DOl: https://doi.org/10.21203/rs.3.rs-32683/v1

License: (1) This work is licensed under a Creative Commons Attribution 4.0 International License. Read Full License 


\section{Abstract}

Background Coronavirus disease 2019 (COVID-19), caused by severe acute respiratory syndrome coronavirus 2 (SARS-CoV-2), which was first identified in December 2019 in Wuhan. This study mainly analyzed the clinical characteristics, imaging features, and prognosis of patients with COVID-19 in Suining, one of China's fourth-tier cities, and Wuhan in 2019 and compared data between the 2 cities.

Methods A retrospective analysis of the epidemiological history, clinical data, symptom presentation, laboratory test results, chest computed tomography (CT) imaging features, treatment measures and prognosis of 68 patients with COVID-19 diagnosed at Wuhan Red Cross Hospital and 17 patients with COVID-19 diagnosed at Suining Central Hospital from January 23, 2020, to February 27, 2020, was conducted.

Results 1) The incidence rate of COVID-19 in Wuhan was 52.99\%oo, and the incidence rate in Suining was 0.04\%oo. The median age of patients with COVID-19 was 40.71 years old in Suining and 56.04 years old in Wuhan. The age of patients with COVID-19 in Wuhan was significantly older than that of patients with COVID-19 in Suining. Among the 68 patients with COVID-19 in Wuhan, 30 (44.1\%) had hypertension, and $25(36.8 \%)$ had diabetes. Three out of the 17 patients in Suining (17.6\%) had hypertension, and 2 patients $(11.8 \%)$ had diabetes. The proportion of patients with diabetes or hypertension in Wuhan was significantly higher than that in Suining $(P<0.05)$. In the clinical classification, there were $1(5.9 \%)$ and 23 (33.8\%) patients with severe COVID-19 in Suining and Wuhan, respectively. The proportion of patients with severe COVID-19 in Wuhan was significantly higher than that in Suining $(P<0.05)$.Fever and cough were the most common clinical symptoms, with 9 cases (52.9\%) and 8 cases (47.1\%) in Suining, respectively, and 54 cases $(79.4 \%)$ and 42 cases (61.8\%) in Wuhan, respectively. There was 1 patient (5.9\%) with COVID-19 with dyspnea in Suining and 23 patients (33.8\%) with COVID-19 with dyspnea in Wuhan; the difference was statistically significant $(P<0.05)$. Chest CT showed that lung consolidation occurred in 2 (11.8\%) and 26 (38.2\%) patients with COVID-19 in Suining and Wuhan, respectively. The proportion of lung consolidation in patients in Wuhan was significantly higher than that in patients in Suining $(P<0.05)$. The laboratory tests suggested that percentage of elevated C-reactive protein (CRP) (58.8\%), ALT (33.8\%), blood glucose (45.6\%), creatine kinase (CK) $33.8 \%$ ) or D-dimer (47.1\%) of patients in Wuhan were significantly increased than those in Suining $(29.4 \%, 5.9 \%, 17.6 \%, 5.9 \%$, and $17.7 \%$, respectively). Moreover, the average length of hospital stay of patients in Wuhan was 17.49 days, which was significantly longer than that of patients in Suining (12.29 days).

Conclusions The incidence of COVID-19 in fourth-tier cities, Suining, in China was significantly lower than that in Wuhan, and the disease severity was generally lower than that in Wuhan, with mostly good prognoses. Advanced age, diabetes, and hypertension are important factors that aggravate COVID-19, while elevated CRP, ALT, blood glucose, CK, and D-dimer levels are important indicators for severe disease.

\section{Methods}


In December 2019, a disease caused by a novel coronavirus was identified in Wuhan, China. In January 2020 , this virus, novel coronavirus (2019-nCoV), was isolated in a laboratory [1, 2] . This disease has attracted worldwide attention. In February 2020, the World Health Organization (WHO) named the disease coronavirus disease 2019 (COVID-19)[3]. The 2019-nCoV genome is highly similar to that identified in bats and is a sarbecovirus subspecies. Subsequently, this virus was renamed severe acute respiratory syndrome coronavirus 2 (SARS-CoV-2) [4]. Epidemiological studies of patients with COVID-19 in China suggest that most patients had been to Wuhan, had lived in Wuhan or had a history of exposure to relevant personnel in Wuhan.

As of 24:00 on February 27, 2020, there were a total of 78,824 diagnosed COVID-19 cases, 2,308 suspected cases, and a total of 2,788 deaths in China. A total of 65,914 cases were diagnosed in Hubei Province, including 48,137 cases and 2,132 deaths in Wuhan. A total of 538 cases were diagnosed in Sichuan Province, and 3 patients died. A total of 17 cases were diagnosed in Suining. The incidence rates were $52.99 \%$ oo in Wuhan and $0.04 \%$ oo in Suining. According to daily real-time epidemic data notifications from the official website of the National Health Commission of the People's Republic of China, the incidence and mortality rates for patients in Wuhan were much higher than those for patients in other areas in China. A comparative analysis of patients with COVID-19 in first-tier cities, such as Beijing, Jiangsu and Wuhan, found that the symptoms of patients in Wuhan were more severe than those of patients in other two cities and that the mortality rate for patients in Wuhan was higher $[5,6]$. However, no study has been conducted to compare cases in Wuhan with cases in fourth-tier cities in China. This study mainly analyzed the epidemiological characteristics, clinical data, and prognosis of patients with COVID19 in the fourth-tier cities in China and in Wuhan and compared data between the 2 cities.

\section{Objects and methods}

\section{Research subjects}

We retrospectively analyzed the cases of 68 patients with COVID-19 diagnosed at Wuhan Red Cross Hospital (Wuhan, China) and 17 patients with COVID-19 diagnosed at Suining Central Hospital(Suining, China) from January 23, 2020, to February 27, 2020. Diagnostic criteria were established according to the Chinese Clinical Guidelines for COVID-19 Pneumonia Diagnosis and Treatment (5th version) proposed by the National Health Commission of China. Patients who had positive SARS-CoV-2 nucleic acid test results (pharyngeal swabs or deep sputum samples) using real-time reverse-transcriptase polymerasechain-reaction (RT-PCR) detection were included in the study. Laboratory diagnosis was mainly conducted by the following institutions: Chinese Center for Disease Control and Prevention (CDC), Academy of Military Medical Sciences, and Wuhan Institute of Virology. According to the Chinese Clinical Guidelines for COVID-19 Pneumonia Diagnosis and Treatment (5th version), the disease severity in patients with COVID-19 was classified as mild, moderate, severe or critically severe based on clinical symptoms, the presence of pneumonia, the severity of pneumonia, and the presence of respiratory failure, shock, or other organ function failure. Patients with mild COVID-19 had mild clinical symptoms and with no pneumonia features on imaging, patients with moderate COVID-19 had fever or respiratory symptoms and with 
pneumonia features on imaging, patients with severe COVID-19 had respiratory distress with a respiratory rate $(\mathrm{RR}) \geq 30$ times/min, percutaneous oxygen saturation $(\mathrm{SpO} 2) \leq 93 \%$ under a resting state or partial pressure of oxygen $(\mathrm{PaO} 2) /$ partial pressure of oxygen(FiO2 $) \leq 300 \mathrm{mmHg}$ ), and patients with critically severe COVID-19 presented shock or respiratory failure, required mechanical ventilation or exhibited other organ failure, requiring intensive care unit (ICU) monitoring.

\section{Methods}

The general information, epidemiological characteristics, clinical symptoms and signs, laboratory examination data at admission, imaging features, treatment, length of hospital stay, and prognosis of all patients were collected. Laboratory tests included complete blood count (CBC), biochemical blood tests, liver and kidney function, C-reactive protein (CRP) level, procalcitonin level, D-dimer level, and muscle enzyme levels. This study was approved by the Ethics Committee of Wuhan Red Cross Hospital and Suining Central Hospital and the written informed consent was waived because of the retrospective nature of the study.

\section{Statistical methods}

SPSS 17.0 was used for the statistical analysis. Normally distributed measurement data are expressed as the mean $\pm S D$; $t$ tests were performed to compare mean values between 2 samples. Nonnormally distributed measurement data are expressed as the median. Categorical data are expressed as a percentage (\%); the chi-square test or Fisher's exact test was used to compare differences between 2 groups. $P<0.05$ indicated that a difference was statistically significant.

\section{Results}

\section{Demographic and clinical characteristics}

This study included 68 patients with COVID-19 in Wuhan and 17 patients with COVID-19 in Suining. The demographic and clinical characteristics are provided in Table 1. The median age of patients in Suining was 40.71 years old (interquartile range (IQR 22.03-59.39), and the median age of patients in Wuhan was 56.04 years old (IQR 41.64-70.44). The patients in Wuhan were significantly older than those in Suining. However, there was no significant difference in patient sex between the 2 cities. There were 17 patients in Suining, i.e., 8 males (47.1\%) and 9 females (52.9\%), and 68 patients in Wuhan, i.e., 35 males (51.5\%) and 33 females (48.5\%). In terms of epidemiology, the patients in Suining had either traveled or lived in Wuhan before disease onset or had been exposed to patients with confirmed COVID-19 in Suining. The incidence of COVID-19 appeared as family clustering in Suining, as there were 3 families the experienced a clustering of disease onset. In terms of symptoms and signs, fever and cough were the most common symptoms of the 2 groups of patients. There were 9 patients (52.9\%) and 8 patients (47.1\%) with fever and cough, respectively, in Suining, and 54 patients (79.4\%) and 42 patients (61.8\%) with fever and cough, respectively, in Wuhan. The incidences of sore throat (4 patients, $23.5 \%$ ), chills (3 patients, 17.6\%)

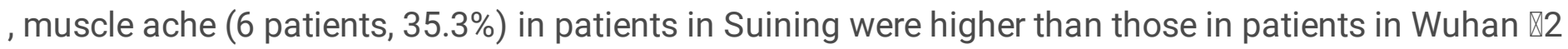


patients $(2.9 \%)$ with sore throat, 1 patient $(1.5 \%)$ with chills and 2 patients $(2.9 \%)$ with muscleache). The patients in Wuhan had othervarious symptoms, including diarrhea (2 patients, $2.9 \%)$, headache (2 patients, $2.9 \%$ ), fatigue (6 patients, $8.8 \%$ ), hemoptysis ( 2 patients, $2.9 \%$ ),inappetence (2 patients, $2.9 \%$ ), and chest distress(7 patients, 10.3\%). Among the patients in Suining, there was 1 patient (5.9\%), 2 patients $(11.1 \%)$ and 5 patients $(29.4 \%)$ with diarrhea, headache and fatigue, respectively. There was no significant difference between the 2 groups. There was only 1 patient with COVID-19 in Suining who experienced dyspnea (5.9\%), but there were 23 patients (33.8\%) in Wuhan who experienced dyspnea, a statistically significant difference $(P<0.05)$. There were 2 asymptomatic patients $(11.8 \%)$ in Suining but none in Wuhan. There was no significant difference in smoking history between the 2 groups of patients. The average incubation period for patients in Suining (10.64 days) was longer than that for patients in Wuhan (7.0 days, $P<0.05)$.

\section{Imaging features}

The chest computed tomography (CT) features of patients with COVID-19 were mostly ground-glass opacities, 14 patients $(82.4 \%)$ in Suining and 40 patients $(58.8 \%)$ in Wuhan presented these features. Ten patients (58.8\%) in Suining presented with patchy shadows in the bilateral lungs, and 31 patients (45.6\%) in Wuhan City presented with patchy shadows in the bilateral lungs, there was no significant difference between the 2 groups. Pulmonary consolidation was observed in 2 patients $(11.8 \%)$ in Suining and 26 patients $(38.2 \%)$ in Wuhan, the difference was statistically significant $(P<0.05)$. The proportion of patients with COVID-19 with pulmonary nodules was relatively low, with 1 patient $(5.9 \%)$ and 2 patients $(2.9 \%)$ in Suining and Wuhan, respectively; there was no significant difference between the 2 groups (Table 1 , Figure 1).

\section{Clinical classification}

Among the 17 COVID-19 patients in Suining, there were 1 case (5.9\%) of mild COVID-19, 14 cases (82.4\%) of moderate COVID-19, 1 case (5.9\%) of severe COVID-19, and 1 case (5.9\%) of critically severe COVID-19. Among the 68 patients in Wuhan, there were no cases of mild COVID-19, 35 cases (51.5\%) of moderate COVID-19, 23 cases (33.8\%) of severe COVID-19, and 10 cases (14.7\%) of critically severe COVID-19. The proportion of patients with moderate COVID-19 in Suining was significantly higher than that of patients with moderate COVID-19 in Wuhan, while the proportion of patients with severe COVID-19 in Wuhan was significantly higher than that of patients with severe COVID-19 in Suining $(P<0.05$, Table 1$)$.

\section{Comorbidities}

There were 6 patients with COVID-19 with hyperlipidemia (35.3\%) in Suining but only 2 patients with COVID-19 with hyperlipidemia (2.9\%) in Wuhan City; the difference was significantly different $(P<0.05)$. However, 30 of the 68 patients with COVID-19 in Wuhan (44.1\%) had hypertension, and 25 patients (36.8\%) had diabetes. Three of the 17 patients in Suining (17.6\%) had hypertension, and 2 patients (11. $8 \%)$ had diabetes. The proportion of patients with COVID-19 with diabetes or hypertension in Wuhanwas significantly higher than that of patients with COVID-19 with diabetes or hypertension in Suining $(P<0.05)$. 
Among the patients in Suining, 1 patient (5.9\%) had rheumatic heart disease, and 2 patients $(11.8 \%)$ were hepatitis B virus (HBV) carriers. The comorbidities in patients with COVID-19 in Wuhan also included rheumatoid arthritis (1 patient, 1.5\%), gastric ulcer (1 patient, 1.5\%), chronic hepatitis B (2 patients, $2.9 \%)$, coronary atherosclerotic heart disease (2 patients, $2.9 \%)$, chronic nephritis (2 patients, $2.9 \%)$, anemia (1 patient, $1.5 \%)$, cerebral infarction (2 patients, $2.9 \%$ ), Alzheimer's disease (1 patient, $1.5 \%$ ), hypothyroidism (1 patient, $1.5 \%)$, and chronic renal insufficiency (2 patients, $2.9 \%)$.

\section{Treatments and prognosis}

Antiviral therapy and antibiotics were commonly used in COVID-19 treatments. 16 patients in Suining $(94.1 \%)$ received antiviral therapy or antibiotics, respectively, and 66 patients $(97.1 \%)$ and 54 patients $(79.4 \%)$ in Wuhan received antiviral therapy or antibiotics, respectively. There was no significant difference between the 2 groups. In terms of other treatment, in Suining, 1 patient (5.9\%) received antifungals, 2 patients (11.8\%) received steroids, 17 patients (100\%) received traditional Chinese medicine, 5 patients $(29.4 \%)$ received thymosin, and 3 patients $(17.6 \%)$ received immunoglobulin supportive treatments. In Wuhan, 3 patients (4.4\%), 14 patients (20.6\%), 9 patients (13.2\%), 12 patients $(17.6 \%)$, and 30 patients $(44.1 \%)$ received antifungal, steroids, traditional Chinese medicine, thymosin, and immunoglobulin supportive treatments, respectively. More patients in Wuhan than in Suining received immunoglobulin supportive treatments, and more patients in Suining than in Wuhan were treated with Chinese medicine $(P<0.05)$. One patient $(5.9 \%)$ in Suining received plasma exchange therapy, and 1 patient $(1.5 \%)$ in Wuhan received hemodialysis. Two patients $(11.8 \%)$ in Suining received mechanical ventilation, and 27 patients (39.7\%) in Wuhan received mechanical ventilation, the difference was statistically significant $(P<0.05)$. The average length from symptom onset to hospital visit was approximately 8.44 days(IQR, 1.67 to 15.21$)$ in Wuhan and 4.47days(IQR, 0.04 to 8.9) in Suinning, the time of hospital visit of patients in Wuhan was longer than that in Suining.The average length of hospital stay of patients in Suining was 12.29 days (IQR, 8.92 to 15.66), significantly shorter than that of patients in Wuhan (17.49 days, IQR, 6.59 to 28.39$)(P<0.05)$. As of February 27, 2020, 2 patients $(11.8 \%)$ were still hospitalized in Suining, and 19 patients (27.9\%) were still hospitalized in Wuhan. Fifteen patients (88.2\%) were discharged in Suining, and 43 patients (63.2\%) were discharged in Wuhan. Of the patients in Wuhan, 6 died (8.8\%); no deaths were reported in Suining (Table 1). 
Table 1

Demographics, clinical characteristics of patients with 2019-nCoV in Suining and Wuhan.

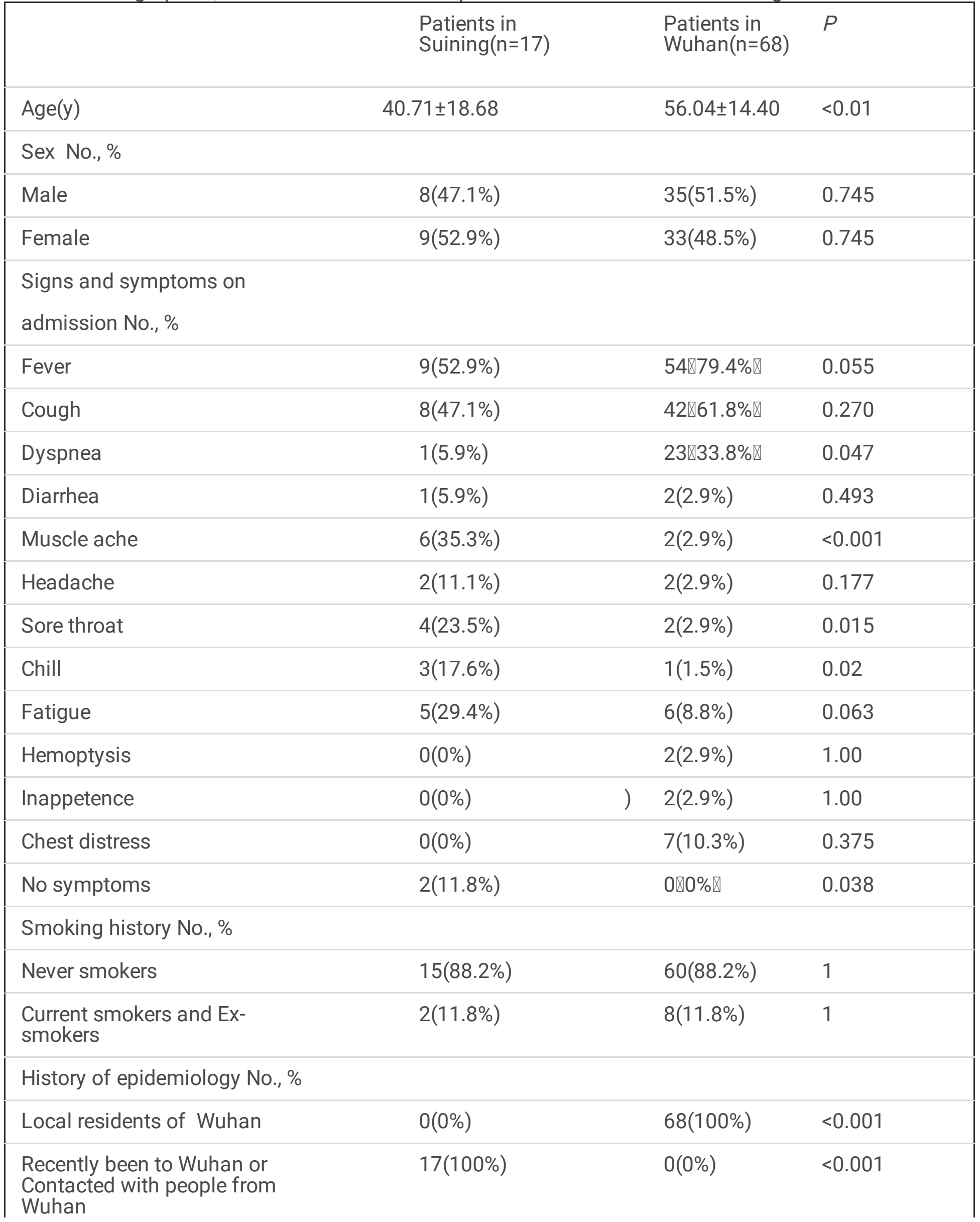




\begin{tabular}{|c|c|c|c|}
\hline Incubation period(days) & $10.64 \pm 10.40$ & $7.0 \pm 3.79$ & 0.021 \\
\hline \multicolumn{4}{|l|}{ Chest CT findings } \\
\hline \multicolumn{4}{|l|}{ No., \% } \\
\hline Ground-glass opacity & $14 \rrbracket 82.4 \% \rrbracket$ & $40 \bigotimes 58.8 \% \rrbracket$ & 0.071 \\
\hline patchy shadows & $10 \otimes 58.8 \% \rrbracket$ & $31 \otimes 45.6 \% \rrbracket$ & 0.329 \\
\hline Pulmonary consolidation & $2 \searrow 11.8 \% \rrbracket$ & $26 \rrbracket 38.2 \% \rrbracket$ & 0.038 \\
\hline Pulmonary nodule & $1 \rrbracket 5.9 \% \rrbracket$ & $2 \varangle 2.9 \% \rrbracket$ & 0.493 \\
\hline \multicolumn{4}{|l|}{ Clinical classification No., \% } \\
\hline Mild type & $1 \otimes 5.9 \% \rrbracket$ & $0 \rrbracket 0 \% \rrbracket$ & 0.2 \\
\hline Moderate type & $14 \rrbracket 82.4 \% \rrbracket$ & $35 \rrbracket 51.5 \% \rrbracket$ & 0.021 \\
\hline Severe type & $1 \rrbracket 5.9 \% \rrbracket$ & $23 \rrbracket 33.8 \% \rrbracket$ & 0.047 \\
\hline Critically type & $1 \rrbracket 5.9 \% \rrbracket$ & $10 \bigotimes 14.7 \% \rrbracket$ & 0.572 \\
\hline \multicolumn{4}{|l|}{ Comorbidities No., \% } \\
\hline hypertension & $3(17.6 \%)$ & $30(44.1 \%)$ & 0.045 \\
\hline diabetes mellitus & $2(11.8 \%)$ & $25(36.8 \%)$ & 0.048 \\
\hline hyperlipidemia & $6(35.3 \%)$ & $2(2.9 \%)$ & $<0.001$ \\
\hline heumatic heart disease & $1 \rrbracket 5.9 \% \rrbracket$ & 0 & 0.200 \\
\hline hepatitis B virus carrier & $2(11.8 \%)$ & 0 & 0.03 \\
\hline rheumatoid arthritis & 0 & $1(1.5 \%)$ & 1 \\
\hline Gastric ulcer & 0 & $1(1.5 \%)$ & 1 \\
\hline chronic viral hepatitis B & 0 & $2 \bowtie 2.9 \% \rrbracket$ & 1 \\
\hline coronary heart disease & 0 & $2 \bowtie 2.9 \% \rrbracket$ & 1 \\
\hline chronic nephritis & 0 & $2 \bowtie 2.9 \% \bigotimes$ & 1 \\
\hline anemia & 0 & $1(1.5 \%)$ & 1 \\
\hline cerebral infarction & 0 & $2 \rrbracket 2.9 \% \bigotimes$ & 1 \\
\hline Alzheimer's disease & 0 & $1(1.5 \%)$ & 1 \\
\hline hypothyroidism & 0 & $1(1.5 \%)$ & 1 \\
\hline chronic renal insufficiency & 0 & $2 \varangle 2.9 \% \rrbracket$ & 1 \\
\hline
\end{tabular}




\begin{tabular}{|c|c|c|c|}
\hline Antiviral treatment & $16(94.1 \%)$ & $66(97.1 \%)$ & 0.493 \\
\hline Antibiotic treatment & $16(94.1 \%)$ & $54(79.4 \%)$ & 0.286 \\
\hline Antifungal medications & $1(5.9 \%)$ & $3(4.4 \%)$ & 1 \\
\hline steroidstherapy & $2(11.8 \%)$ & $14(20.6 \%)$ & 0.627 \\
\hline Mechanical ventilation & $2(11.8 \%)$ & $27(39.7 \%)$ & 0.03 \\
\hline Traditional Chinese medicine & $17(100 \%)$ & $9(13.2 \%)$ & $<0.001$ \\
\hline Plasma exchange & $1 \rrbracket 5.9 \% \bigotimes$ & 0 & 0.200 \\
\hline Use of thymosin & $5(29.4 \%)$ & $12 \llbracket 17.6 \% \rrbracket$ & 0.456 \\
\hline $\begin{array}{l}\text { Use of intravenous } \\
\text { immunoglobin }\end{array}$ & $3(17.6 \%)$ & $30 \rrbracket 44.1 \% \rrbracket$ & 0.045 \\
\hline Use of hemodialysis & 0 & $1(1.5 \%)$ & 1 \\
\hline Time of hospital visit (days) & $4.47 \pm 4.43$ & $8.44 \pm 6.77$ & 0.024 \\
\hline Hospital stay(days) & $12.29 \pm 3.37$ & $17.49 \pm 10.9$ & 0.048 \\
\hline \multicolumn{4}{|l|}{ Clinical outcomes No., \% } \\
\hline Death & 0 & $6(8.8 \%)$ & 0.459 \\
\hline Remained in hospital & $2(11.8 \%)$ & $19(27.9 \%)$ & 0.285 \\
\hline Discharge from hospital & $15(88.2 \%)$ & $43(63.2 \%)$ & 0.048 \\
\hline
\end{tabular}

COVID-19, coronavirus disease 2019, time of hospital visit, the time from symptom onset to hospital visit, $p$ values denoted the comparison between Suining group and Wuhan group.

\section{Laboratory tests}

Laboratory tests showed elevated white blood cell (WBC) counts in 1 patient (5.9\%) in Suining and in 20 of 68 patients $(29.4 \%)$ in Wuhan and reduced WBC counts in 2 patients $(11.8 \%)$ in Suining and 2 of 68 patients (2.9\%) in Wuhan (Table 2),there were no significant differences between the 2 cities. Among the 17 patients with COVID-19 in Suining, $6(35.3 \%)$ had a lower lymphocyte count than normal, while 43 patients $(63.2 \%)$ in Wuhan had a decreased lymphocyte count, with significant difference between the 2 groups. However, the percentage of patients with increased neutrophils in Suining (4 cases, 23.5\%) was significantly lower than that in Wuhan (36 cases, 52.9\%), $(P<0.05)$. Platelet counts were elevated in 6 patients (8.8\%) in Wuhan and reduced in 11 patients (16.2\%) in Wuhan and reduced in $3(17.6 \%)$ patients in Suining. Hemoglobin levelswere decreasedin 36 patients (52.9\%) in Wuhan and in 7 patients $(41.2 \%)$ in Suining. There were no significant differences in platelet counts and hemoglobin levels between the 2 groups of patients. 5 patients (29.4\%) in Suining had CRP levels greater than $10 \mathrm{mg} / \mathrm{L}$, and 40 patients 
(58.8\%) in Wuhan had elevated CRP levels, the percentage of patients with CRP increased in Wuhan were significantly higher than that in Suining $(P<0.05)$.

Among the 17 patients in Suining, 3 patients (17.6\%) had elevated aspartate aminotransferase (AST) levels, 7 patients $(41.2 \%)$ had decreased albumin levels, 1 patient $(5.9 \%)$ had an increased total bilirubin level, 7 patients (41.2\%) with elevated lactate dehydrogenase (LDH) levels, and 8 patients (47.1\%) had elevated procalcitonin levels. Among the 68 patients in Wuhan, 11 patients $(16.2 \%)$ had elevated AST levels, 26 patients (38.2\%) had reduced albumin levels, 3 patients $(4.4 \%)$ had decreased blood glucose levels, 5 patients $(7.4 \%)$ had elevated blood urea nitrogen levels, 9 patients $(13.2 \%)$ had elevated creatinine levels, 37 patients (53.6\%) had elevated LDH levels, 9 patients (13.2\%) had elevated myoglobin levels, and 33 patients (48.5\%) had elevated procalcitonin levels. There were no significant differences between the 2 groups. However, in Suining, 1 patient (5.9\%) had elevated alanine aminotransferase (ALT) levels, 3 patients (17.6\%) had elevated blood glucose levels, and 1 patient $(5.9 \%)$ had increased creatine kinase (CK) levels. Among the patients in Wuhan, 23 patients (33.8\%) had elevated ALT levels, 31 cases (45.6\%) had elevated blood glucose levels, and 23 patients (33.8\%) had elevated CK levels. The proportion of patients with elevated ALT, blood glucose and CK in Suining was significantly lower in Wuhan $(P<0.05)$ (Table 2).

In Suining, there were 8 patients (47.1\%) with prolonged activated partial thromboplastin time (APTT) and 1 patient (5.9\%) with prolonged prothrombin time (PT), and in Wuhan, there were 30 patients (44.1\%) with prolonged APTT and 17 patients (25.0\%) with prolonged PT; there was no difference between the 2 groups. However, 3 patients (17.6\%) in Suining had elevated plasma D-dimer levels, and 32 patients (47.1\%) in Wuhan City had elevated D-dimer levels. The percentage of patients with elevated D-dimer levels in Wuhan was significantly higher than in Suining $(P<0.05)$ ( Table 2$)$. 
Table 2

Laboratory findings of 86 patients with 2019-nCoV in Suining and Wuhan

\begin{tabular}{|c|c|c|c|c|c|c|}
\hline & Patients in & uining $(n=$ & & Patients in $\mathrm{V}$ & uhan $(n=68)$ & $P$ \\
\hline Blood routine No.No. (\%) & & $\begin{array}{l}\text { Normal } \\
\text { rang }\end{array}$ & & $\begin{array}{l}\text { Normal } \\
\text { rang }\end{array}$ & & \\
\hline \multirow[t]{3}{*}{ 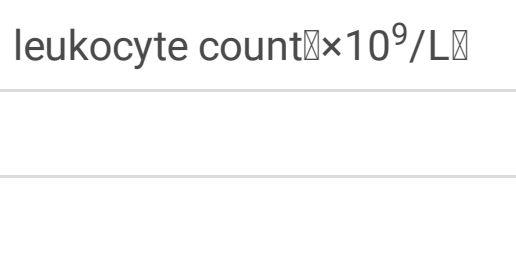 } & & $3.5-9.5$ & & $3.7-10$ & & \\
\hline & increased & & $1(5.9 \%)$ & & $20(29.4 \%)$ & 0.09 \\
\hline & decreased & & $2(11.8 \%)$ & & $2(2.9 \%)$ & 1.000 \\
\hline \multirow{2}{*}{$\begin{array}{l}\text { Lymphocyte count } \\
\square \times 10^{9} \text { /L】 }\end{array}$} & & $1.1-3.2$ & & $0.8-4.0$ & & \\
\hline & decreased & & $6(35.3 \%)$ & & $43(63.2 \%)$ & 0.037 \\
\hline \multirow[t]{2}{*}{ Neutrophil count $¥ \% \square$} & & $40-75$ & & $43-77$ & & \\
\hline & increased & & $4(23.5 \%)$ & & $36(52.9 \%)$ & 0.03 \\
\hline \multirow[t]{3}{*}{ Platelet count $\rrbracket \times 10^{9} / \mathrm{L} \rrbracket$} & & $\begin{array}{l}125- \\
350\end{array}$ & & $85-320$ & & \\
\hline & increased & & 0 & & $6(8.8 \%)$ & 0.459 \\
\hline & decreased & & $3(17.6 \%)$ & & $11(16.2 \%)$ & 1.000 \\
\hline \multirow[t]{2}{*}{ Haemoglobin $(\mathrm{g} / \mathrm{L})$} & & $\begin{array}{l}130- \\
175\end{array}$ & & $\begin{array}{l}110- \\
172\end{array}$ & & \\
\hline & decreased & & $7(41.2 \%)$ & & $36(52.9 \%)$ & 0.386 \\
\hline $\begin{array}{l}\text { C-reactive protein level } \geq 10 \\
\mathrm{mg} / \mathrm{L} \text { No.No. (\%) }\end{array}$ & & & $5(29.4 \%)$ & & $40(58.8 \%)$ & 0.03 \\
\hline $\begin{array}{l}\text { Blood biochemistry No.No. } \\
(\%)\end{array}$ & & $\begin{array}{l}\text { Normal } \\
\text { rang }\end{array}$ & & & & \\
\hline \multirow{2}{*}{$\begin{array}{l}\text { Alanine } \\
\text { aminotransferase(U/L) }\end{array}$} & & $9-50$ & & $0-40$ & & \\
\hline & increased & & $1(5.9 \%)$ & & $23(33.8 \%)$ & 0.022 \\
\hline \multirow[t]{2}{*}{$\begin{array}{l}\text { Aspartate } \\
\text { aminotransferase(U/L) }\end{array}$} & & $15-40$ & & $0-45$ & & \\
\hline & increased & & $3(17.6 \%)$ & & $11(16.2 \%)$ & 1.000 \\
\hline \multirow[t]{2}{*}{ Albumin $₫ \mathrm{~g} / \mathrm{L} \rrbracket$} & & $40-55$ & & $35-55$ & & \\
\hline & decreased & & $7(41.2 \%)$ & & $26(38.2 \%)$ & 1.000 \\
\hline \multirow[t]{2}{*}{ Total bilirubin $(\mu \mathrm{mol} / \mathrm{L})$} & & $5.1-28$ & & $2-25$ & & \\
\hline & increased & & $1(5.9 \%)$ & & $6(8.8 \%)$ & 1.000 \\
\hline
\end{tabular}


Glucose(mmol/L)

3.89-

3.6-

6.11

6.11

\begin{tabular}{|c|c|c|c|c|c|}
\hline & increased & $3(17.6 \%)$ & & $31(45.6 \%)$ & 0.035 \\
\hline & decreased & 0 & & $3(4.4 \%)$ & 1.000 \\
\hline $\begin{array}{l}\text { Blood urea } \\
\text { nitrogen(mmol/L) }\end{array}$ & & $\begin{array}{l}2.86- \\
8.2\end{array}$ & $3.1-8$ & & \\
\hline
\end{tabular}

\begin{tabular}{|c|c|c|c|c|c|c|}
\hline & increased & & 0 & & $5(7.4 \%)$ & 0.564 \\
\hline \multirow[t]{2}{*}{ Serum creatinine $(\mu \mathrm{mol} / \mathrm{L})$} & & $57-111$ & & $57-97$ & & \\
\hline & increased & & 0 & & $9(13.2 \%)$ & 0.252 \\
\hline \multirow[t]{2}{*}{ Creatine kinase (U/L) } & & $50-310$ & & 24-195 & & \\
\hline & increased & & $1(5.9 \%)$ & & $23(33.8 \%)$ & 0.047 \\
\hline \multirow{2}{*}{$\begin{array}{l}\text { Lactate } \\
\text { dehydrogenase(U/L) } \\
\text { No.No. (\%) }\end{array}$} & & $\begin{array}{l}120- \\
250\end{array}$ & & $90-250$ & & \\
\hline & increased & & $7(41.2 \%)$ & & $37(53.6 \%)$ & 0.358 \\
\hline \multirow[t]{2}{*}{$\begin{array}{l}\text { Myoglobin(ng/ml) No.No. } \\
(\%)\end{array}$} & & $0-154.9$ & & $\begin{array}{l}0- \\
90000\end{array}$ & & \\
\hline & increased & & 0 & & $9(13.2 \%)$ & 0.252 \\
\hline $\begin{array}{l}\text { Procalcitonin level } \geq 0.5 \\
\mathrm{ng} / \mathrm{ml} \text {-No.No. (\%) }\end{array}$ & & & $8(47.1 \%)$ & & $33(48.5 \%)$ & 0.914 \\
\hline $\begin{array}{l}\text { Coagulation function } \\
\text { No.No. (\%) }\end{array}$ & & $\begin{array}{l}\text { Normal } \\
\text { rang }\end{array}$ & & & & \\
\hline \multirow{2}{*}{$\begin{array}{l}\text { Activated partial } \\
\text { thromboplastin time (s) }\end{array}$} & & $26-40$ & & $20-40$ & & \\
\hline & increased & & $8(47.1 \%)$ & & $30(44.1 \%)$ & 0.827 \\
\hline \multirow[t]{2}{*}{ Prothrombin time (s) } & & $11-14.5$ & & $9-13$ & & \\
\hline & increased & & $1(5.9 \%)$ & & $17(25.0 \%)$ & 0.163 \\
\hline D-dimer( $\mu \mathrm{g} / \mathrm{L})$ & & $0-0.5$ & & $0-0.55$ & & \\
\hline \multicolumn{7}{|l|}{ No.No. (\%) } \\
\hline & increased & & $3(17.6 \%)$ & & $32(47.1 \%)$ & 0.028 \\
\hline
\end{tabular}




\section{Discussion}

Coronaviruses are RNA viruses that are widely distributed in humans and mammals [7]. Severe acute respiratory syndrome coronavirus (SARS-CoV) in 2002 and Middle East respiratory syndrome-related coronavirus (MERS-CoV) in 2012 caused disease outbreaks and severe symptoms[8-10]. SARS-CoV-2 is the seventh known coronavirus infection in humans. COVID-19 is highly infectious, but its mortality rate is much lower than that of SARS and MERS. Studies have shown that fever and cough are the main clinical manifestations of COVID-19[11]. Most patients with COVID-19 have mild disease, however, symptomatic treatment is the only current treatment for COVID-19, and a standard treatment plan has not been established yet. Once conditions become aggravated and complicated with acute respiratory distress syndrome, more than $10 \%$ of patients rapidly die of multiple organ failure [12].

This study included 17 patients with COVID-19 in Suining and 68 patients with COVID-19 in Wuhan. Recent studies have shown that the prevalence rate of COVID-19 in males and females is close to 1:1 [13]. Our experimental results show that rate of COVID-19 in males and females is also close to 1:1 and there was no significant difference in sex between patients in 2 cities. As of February 27, a total of 48,137 cases were diagnosed in Wuhan, with a total of 2,132 deaths, a total of 17 cases were diagnosed in Suining, with no deaths. The incidence rate in Wuhan was $52.99 \%$ oo, significantly higher than that in Suining (0.04\%oo). Since the identification of more than 10 cases of COVID-19 in December 2019 in Wuhan, the disease has rapidly spread throughout the world. SARS-CoV-2 mainly spreads through human respiratory droplets and direct contact. Recently, researchers in Italy found that SARS-CoV-2 RNA can exist on particles in outdoor air and that SARS-CoV-2 can cluster with outdoor particulate matter and enhance the persistence of the virus in the atmosphere by reducing the diffusion coefficient [14]. Studies from Wuhan University also found that SARS-CoV-2 can also spread through aerosols [15]. Wuhan is located on the railway line connecting Beijing and Guangzhou and is the crossroads for the Yangtze River connecting Chongqing and Shanghai. Wuhan is a major transportation hub in China, with high population density [16].In addition, the number of patients with COVID-19 in Wuhan was high, and the large viral load of SARS-CoV-2 in the air in this region, the long persistence and its transmission capacity led to the continuous increase in patient numbers in Wuhan, resulting in a sharp increase in the number of patients and aggravation of the disease in Wuhan. For Suining, a fourth-tier city in China, with low population density, the incidence of COVID-19 was mostly associated with personnel who have been to or were from Wuhan, and the low population density and small viral load of SARS-CoV-2 in the air resulted in a small number of cases. In addition, our study showed that the incubation period of COVID-19 in patients in Wuhan was significantly shorter than that in Suining, which was related to the larger viral load of SARS-CoV-2 in the air in Wuhan than that in Suining. Therefore, the incidence rate in Wuhan was higher than that in fourth-tier city.

Similar to patients with MERS-CoV[17], diabetes and cardiovascular diseases are common underlying diseases in COVID-19 patients. Wang et al. conducted a systematic analysis of clinical big data related to COVID-19 patients, the meta-analysis of the risk of severe diseases and death found that chronic diseases such as hypertension, cardiovascular disease, chronic renal disease, and diabetes significantly 
increased the risk of COVID-19 [18]. Our results showed that the rates of patients with COVID-19 with hypertension or diabetes in Wuhan were $44.1 \%$ and $36.8 \%$, respectively, higher than those in Suining (11.8\% patients with diabetes and $17.6 \%$ patients with hypertension).Moreover, patient age at onset in Wuhan was older than that in Suining, and dyspnea in Wuhan was more common than that in Suining. The clinical symptoms of patients in both cities were mainly fever and cough, with fewer digestive tract symptoms, which is consistent with the results reported by Guan et al. [19]. Huang reported that patients with severe COVID-19 in Wuhanwere more severe than other places [20]. Our study showed that, in the clinical classification, there were more patients with severe COVID-19 (33.8\%) in Wuhan than in Suining (5.9\%). Additionally, we also found that the average length of hospital stay of patients with COVID-19 in Wuhan (17.49 days) was much longer than that of patients in Suining (12.29 days) and that the discharge rate for patients in Wuhan (63.2\%) was lower than that in Suining (88.2\%). Therefore, the results showed that the disease conditions in Wuhan were worse and the length of hospital stay was longer than those in fourth-tier city of China, which may be related to the fact that patients in Wuhan with older age and more underlying diseases, such as diabetes and hypertension, were more likely to develop severe COVID-19.

Consistent with the findings by Wang et al. [21],our laboratory test results suggested that the proportions of patients with elevated CRP (58.8\%), ALT (33.8\%), blood glucose (45.6\%), CK (33.8\%) or D-dimer (47.1\%) levels in Wuhan were significantly higher than those in Suining $(29.4 \%, 5.9 \%, 17.6 \%, 5.9 \%$, and $17.6 \%$, respectively). Chen et al. found that ALT, LDH, D-dimer, CRP and ferritin levels in patients with severe COVID-19 were higher than those in common patients [22]. Chest CT showed that the rate of lung consolidation in patients in Wuhan (38.2\%) was much higher than that in patients in Suining (11.8\%). In addition, more patients in Wuhan than in Suining received immunoglobulin supportive treatments and mechanical ventilation. The results confirmed that the conditions of patients in Wuhan were more severe than the conditions of patients in Suining, and our results showed that increases in CRP, ALT, blood glucose, CK and D-dimer were important indicators of severe COVID-19.

The MuLBSTA scoring system is a new type of early warning scoring system for the risk of death from viral pneumonia; factors included in the score include multilobular infiltration, lymphopenia, bacterial coinfection, smoking history, hypertension and age older than 60 years [23]. The deaths in this study were consistent with the MuLBSTA score. Lymphocyte count and neutrophil abnormalities were observed in patients with COVID-19 both in Wuhan and Suining. The proportion of patients with a lower lymphocyte count in Wuhan were remarkable higher than that in Suining. Additionally, patients with severe COVID-19 had decreased lymphocyte counts, indicating that the virus can attack the human lymphatic system, especially $T$ lymphocytes, weaken immunity, produce a cytokine storm and cause secondary bacterial infection, which can rapidly develop into acute respiratory distress syndrome (ARDS), shock, multiple organ failure, and eventually death.

The average length from symptom onset to hospital visit was approximately 8.44 days in Wuhan and 4.47days in Suinning. The main manifestations of COVID-19 were coughing and fever. Most patients in Wuhan initially thought that they had a common cold and did not seek hospital treatment, sothe time of 
hospital visit was long. On the other hand, the first confirmed case occurred in late January 2020 in Suining. During this period, awareness of COVID-19 has been strengthened and people saw a doctor immediately once they had cough or any discomfort, which led to a short time of hospital visit. Moreover, strict investigations were being conducted in various regions to promptly block sources of infection and cut off transmission routes during this time. In addition, medical resources in Wuhan were scarce and Suining had relatively adequate medical resources. Therefore, the disease in fourth-tier city, Suining, was milder than that in Wuhan and incidence rate in Wuhan was higher than that in Suining.

\section{Conclusions}

In summary, our research results show that the incidence of COVID-19 in fourth-tier city in China was significantly lower than that in Wuhan and that disease severity was also significantly lower than that in Wuhan. The occurrence of COVID-19 is mainly clustered, and advanced age, diabetes, hypertension, and cardiovascular diseases can exacerbate the disease. Increases in CRP, ALT, blood glucose, CK, and Ddimer levels can indicate disease severity. Early diagnosis and treatment are important measures to prevent disease aggravation.

\section{Declarations}

\section{Acknowledgements}

We extend special thanks for the contribution of consultant experts and healthcare practitioners from Wuhan Red Cross Hospital and Suining Central Hospital for their participation. The authors thank American Journal Experts (AJE) for providing language help.

\section{Authors' contributions}

XJW, CPW had full access to all of the data in the study and take

responsibility for the integrity of the data and the accuracy of the data analysis; $\mathrm{ZGH}, \mathrm{MCL}$ designed this study, XBL, BLJ ,GYH analysed and interpreted data of this study; RQ, JW,LL drafted the manuscript; $\mathrm{XJW}, \mathrm{MCL}, \mathrm{ZGH}$ made critical revision of the article for important intellectual content; CPW got the funding for this study; All authors agreed with the results and conclusions of this article.

All authors read and approved the final manuscript.

\section{Funding}

This work was supported by the Sichuan Coronavirus Prevention and Control Technology Project (2020PTJSGG007).

\section{Availability of data and materials}


The datasets used and/or analyzed during the current study are available from the corresponding author on request.

\section{Ethics approval and consent to participate}

This study was approved by the Ethics Committee of Wuhan Red Cross Hospital and Suining Central Hospital and the written informed consent was waived because of the retrospective nature of the study.

\section{Consent for publication}

Not applicable.

\section{Competing interests}

The authors declare that they have no competing interests.

\section{Author details}

1 Department of Respiratory Respiratory and Critical Care Medicine, 2 Oral and Maxillofacial Surgery, Suining Central Hospital, Suining 629000, China; 3 Department of Respiratory Respiratory and Critical Care Medicine, the Second Affiliated Hospital of Chongqing Medical University $\llbracket$ Chongqing 400000, China

\section{References}

1. [1] Lu H, Stratton CW, Tang YW. Outbreak of pneumonia of unknown etiology in Wuhan, China: The mystery and the miracle. J Med Virol. 2020;92(4):401-2.

2. [2] Hui DS, E IA, Madani TA, Ntoumi F, Kock R, Dar O, et al. The continuing 2019nCoV epidemic threat of novel coronaviruses to global health - The latest 2019 novel coronavirus outbreak in Wuhan, China. Int J Infect Dis. 2020;91:264-6.

3. [3] WHO. World experts and funders set priorities for COVID-19 research. Feb 12, 2020.

4. [4] Coronaviridae Study Group of the International Committee on Taxonomy of V. The species Severe acute respiratory syndrome-related coronavirus: classifying 2019-nCoV and naming it SARS-CoV-2. Nat Microbiol. 2020;5(4):536-44.

5. [5] Tian S, Hu N, Lou J, Chen K, Kang X, Xiang Z, et al. Characteristics of COVID-19 infection in Beijing. J Infect. 2020;80(4):401-6. 
6. [6] Wu J, Liu J, Zhao X, Liu C, Wang W, Wang D, et al. Clinical Characteristics of Imported Cases of COVID-19 in Jiangsu Province: A Multicenter Descriptive Study. Clin Infect Dis. 2020.

7. [7] Fehr AR, Perlman S. Coronaviruses: an overview of their replication and pathogenesis. Methods Mol Biol. 2015;1282:1-23.

8. [8] Song HD, Tu CC, Zhang GW, Wang SY, Zheng K, Lei LC, et al. Cross-host evolution of severe acute respiratory syndrome coronavirus in palm civet and human. Proc Natl Acad Sci U S A. 2005;102(7):2430-5.

9. [9] Haagmans BL, Al Dhahiry SHS, Reusken CBEM, Raj VS, Galiano M, Myers R, et al. Middle East respiratory syndrome coronavirus in dromedary camels: an outbreak investigation. The Lancet Infectious Diseases. 2014;14(2):140-5.

10. [10] Azhar EI, El-Kafrawy SA, Farraj SA, Hassan AM, Al-Saeed MS, Hashem AM, et al. Evidence for camel-to-human transmission of MERS coronavirus. N Engl J Med. 2014;370(26):2499-505.

11. [11] Guan WJ, Ni ZY, Hu Y, Liang WH, Ou CQ, He JX, et al. Clinical Characteristics of Coronavirus Disease 2019 in China. N Engl J Med. 2020;382(18):1708-20.

12. [12] Chen N, Zhou M, Dong X, Qu J, Gong F, Han Y, et al. Epidemiological and clinical characteristics of 99 cases of 2019 novel coronavirus pneumonia in Wuhan, China: a descriptive study. The Lancet. 2020;395(10223):507-13.

13. [13] Zhang JJ, Dong X, Cao YY, Yuan YD, Yang YB, Yan YQ, et al. Clinical characteristics of 140 patients infected with SARS-CoV-2 in Wuhan, China. Allergy. 2020.

14. [14] Setti L, Passarini F, De Gennaro G, Barbieri P, Pallavicini A, Ruscio M, et al. Searching for SARS-COV-2 on Particulate Matter: A Possible Early Indicator of COVID19 Epidemic Recurrence. Int J Environ Res Public Health. 2020;17(9).

15. [15] Liu Y, Ning Z, Chen Y, Guo M, Liu Y, Gali NK, et al. Aerodynamic analysis of SARS-CoV-2 in two Wuhan hospitals. Nature. 2020.

16. [16] Zhong P, Guo S, Chen T. Correlation between travellers departing from Wuhan before the Spring Festival and subsequent spread of COVID-19 to all provinces in 
China. J Travel Med. 2020;27(3).

17. [17] Badawi A, Ryoo SG. Prevalence of comorbidities in the Middle East respiratory syndrome coronavirus (MERS-CoV): a systematic review and meta-analysis. Int J Infect Dis. 2016;49:129-33.

18. [18] Wang X, Fang X, Cai Z, Wu X, Gao X, Min J, et al. Comorbid Chronic Diseases and Acute Organ Injuries Are Strongly Correlated with Disease Severity and Mortality among COVID-19 Patients: A Systemic Review and Meta-Analysis. Research (Wash D C). 2020;2020:2402961.

19. [19] Wang D, Hu B, Hu C, Zhu F, Liu X, Zhang J, et al. Clinical Characteristics of 138 Hospitalized Patients With 2019 Novel Coronavirus-Infected Pneumonia in Wuhan, China. JAMA. 2020.

20. [20] Huang C, Wang Y, Li X, Ren L, Zhao J, Hu Y, et al. Clinical features of patients infected with 2019 novel coronavirus in Wuhan, China. The Lancet. 2020;395(10223):497-506.

21. [21] Wang F, Hou H, Luo Y, Tang G, Wu S, Huang M, et al. The laboratory tests and host immunity of COVID-19 patients with different severity of illness. JCI Insight. 2020;5(10).

22. [22] Chen G, Wu D, Guo W, Cao Y, Huang D, Wang H, et al. Clinical and immunological features of severe and moderate coronavirus disease 2019. J Clin Invest. 2020;130(5):2620-9.

23. [23] Guo L, Wei D, Zhang X, Wu Y, Li Q, Zhou M, et al. Clinical Features Predicting Mortality Risk in Patients With Viral Pneumonia: The MuLBSTA Score. Front Microbiol. 2019;10:2752.

\section{Figures}



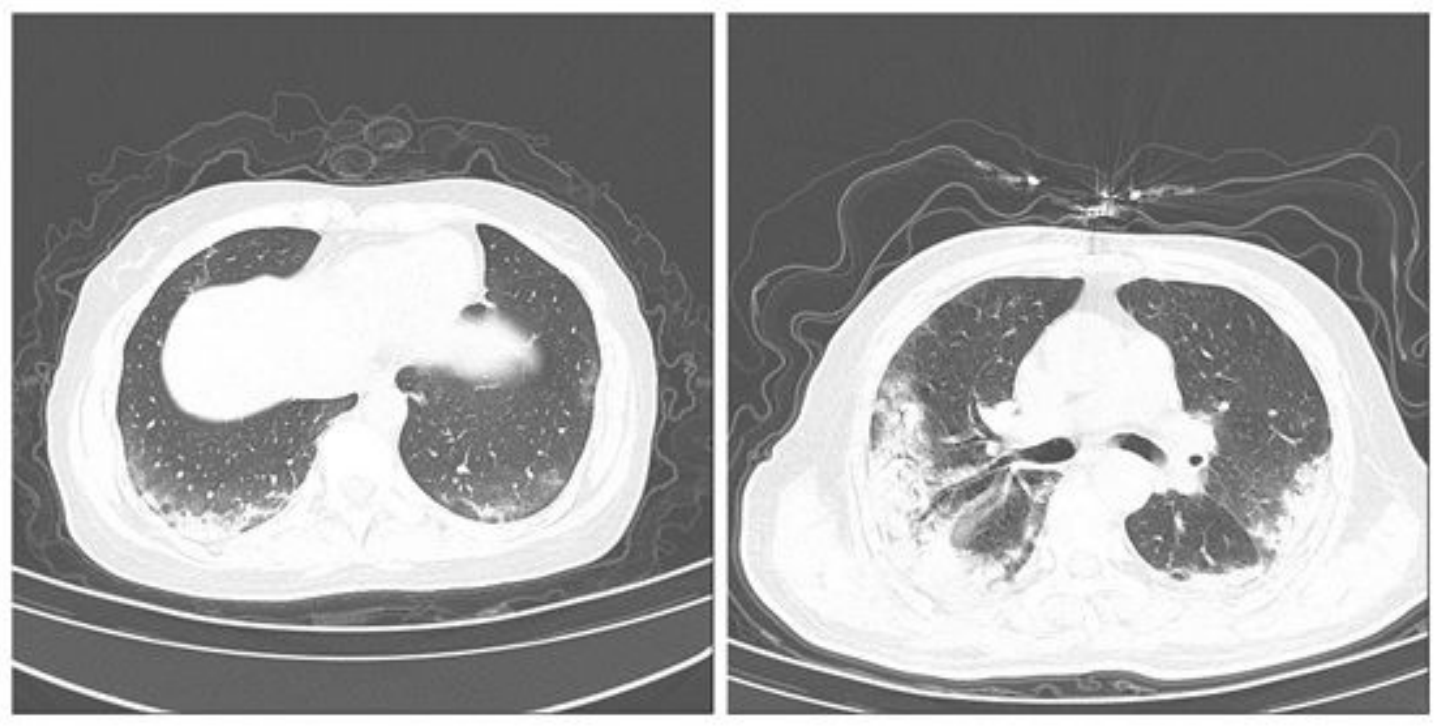

Figure 1

Representativechest CTs of patients A, Small subpleural nodules in the upper middle lobe of the right lung, B, Ground-glass opacities in the subpleural region of the lower lobes of the bilateral lungs, C, Patchy opacities in lower lobes of the bilateral lungs, D, Consolidation at the bilateral lung periphery, with bronchial signs. 